\title{
Pagamento de dividendos sobre o uso de dados digitais: projeções para o cenário brasileiro
}

Um ponto que todas as cinco maiores companhias abertas listadas nos Estados Unidos possuem em comum é a aplicação direta de dados digitais em suas operaçõe diárias. Seja através de anúncios direcionados ou estudos comportamentais para aprimoramento de produtos, os dados digitais são uma relevante forma de rentabilização para as empresas e fonte de vantagem competitiva com a correta aplicação das análises nas atividades. Com as novas legislações acerca do tema de proteção de dados, diversas regras quanto a análise e coleta de dados foram ajustadas e podem afetar o faturamento das companhias. O Brasil, através da LGPD, também protegerá seus usuários e permitirá que cada um seja titular de suas informações digitais. Com a proteção da lei, surgiram movimentos que visam, através da inovação de titularidade das leis de proteção de dados, um pagamento adequado para os usuários pelo constante fluxo de informações que torna possível toda a economia moderna. É possível que a total integração de análise de dados gere mais de 15 trilhões de dólares por ano em valor para as companhias, neste cenário dados podem ser tratados como uma commodity e os usuários, os verdadeiros donos e titulares, devem ir atrás de uma razoável compensação por permitirem uma grande expansão da economia 4.0, na qual dados são o combustível de toda a economia.

Palavras-chave: Dados Digitais; Dividendos; Economia 4.0; GDPR; LGPD.

\section{Dividend payment on the use of digital data: projections for the Brazilian scenario}

\begin{abstract}
One aspect that all five major listed companies in the United States have in common is the direct application of digital data in their daily operations. Whether through targeted advertisements or behavioral studies to improve products, digital data is a relevant form of profitability for companies and a source of competitive advantage with the correct application of analysis in activities. With the new legislation on the subject of data protection, several rules regarding the analysis and collection of data have been adjusted and can affect companies' revenues. Brazil, through the LGPD, will also protect its users and allow each one to own their digital information. With the protection of the law, movements have emerged that aim, through the innovation of ownership of data protection laws, an adequate payment for users for the constant flow of information that makes the whole modern economy possible. It is possible that the total integration of data analysis generates more than 15 trillion dollars per year in value for companies, in this scenario data can be treated as a commodity and the users, the real owners, must go after a reasonable compensation for allowing a great expansion of economy 4.0, in which data are the fuel of the entire economy.
\end{abstract}

Keywords: Digital Data; Dividends; Economy 4.0; GDPR; LGDP.

Topic: Finanças Empresariais

Reviewed anonymously in the process of blind peer
Received: 09/01/2021

Approved: 21/03/2021
Laércio Morais Júnior (iD)

Pontifícia Universidade Católica do Paraná, Brasil.

http://lattes.cnpq.br/9122154036197259

http://orcid.org/0000-0001-9305-5729

laerciomoraisjr@gmail.com
Referencing this:

MORAIS JÚNIOR, L.. Pagamento de dividendos sobre o uso de dados digitais: projeções para o cenário brasileiro. Revista Brasileira de Administração Científica, v.12, n.1, p.9-26, 2021. DOI: http://doi.org/10.6008/CBPC2179-684X.2021.001.0002 


\section{INTRODUÇÃO}

No mundo constantemente conectado as pessoas podem não se dar conta do valor de suas rápidas interações digitais. A economia digital já alcança patamares colossais, em valores de mercado que ultrapassam trilhões de dólares em grandes empresas tecnológicas. Cinco das dez maiores companhias abertas americanas são de tecnologia, na China o padrão é o mesmo, e as duas maiores companhias abertas do país são tecnológicas.

Contudo, poucos se dão conta sobre qual a verdadeira força motriz por trás de todo o valor alcançado, e a resposta é simples: Dados. Dados digitais dos usuários de todo o mundo alimentam a maior indústria atual e torna possível as receitas das titãs tecnológicas. É possível inclusive comparar os dados digitais como o novo petróleo, os pacotes de informações já podem ser considerados commodities, comercializados e originando diversos mercados que giram em torno da troca de informações.

Amazon, Google, Facebook, Microsoft. Nomes de grandes companhias digitais que dominam o novo mercado. Não é surpresa que estas empresas utilizam dos dados comportamentais de seus usuários para fornecer melhores informações, produtos ou direcionar anúncios específicos de acordo com cada perfil. Mas a indústria de dados não se resume a isso. Basicamente toda companhia que nasce neste mercado necessita de grandes catálogos de dados para aperfeiçoar seu funcionamento e direcionar seus negócios. Tradicionais companhias de saúde, bancos, consignatárias de crédito, hotelaria, startups, todas as empresas da economia atual, ainda que não sejam digitais, utilizam de alguma forma a análise de dados e comportamentos em suas operações.

Os pacotes de dados digitais são tão preciosos que há até mesmo um mercado secundário em pleno funcionamento. As chamadas corretoras de dados negociam enormes quantidades de informações para atender diversos públicos e passam anualmente dos bilhões de dólares em faturamento, alimentando novas startups, companhias médicas e até empresas de crédito com os dados pessoais de milhões de pessoas.

Atualmente com algumas novas legislações na União Europeia, Estados Unidos e no Brasil, o usuário passa a ter um controle maior sobre sua privacidade virtual e conhecimento sobre seus registros. Ao tornar os usuários donos e titulares de todos os seus dados, as legislações de proteção de dados permitem que as pessoas possam negociar valores pela coleta e utilização de seus registros e comportamentos. Sendo os dados digitais uma commodity, seus verdadeiros produtores devem ser recompensados pelo seu uso. A alternativa mais atrativa para remuneração dos usuários é a do grupo americano Data Dividend Project, que postula por um pagamento de dividendos recorrente pela utilização dos dados digitais dos usuários.

Alguns cálculos demonstraram que nos Estados Unidos, uma família de 4 pessoas pode receber até 20 mil dólares anuais em dividendos pela utilização de seus dados. No Brasil, a estimativa realizada no presente artigo é um tanto quanto menor, mas pode ser viável para um grupo de pessoas.

Toda a economia do futuro está fundada na utilização dos dados digitais e as pessoas não estão recebendo um único centavo da construção deste mercado. $O$ pagamento de dividendos aos usuários pela exploração dos dados não apenas é uma solução econômica viável, mas também visa a dignidade da pessoa 
humana no ambiente virtual.

\section{METODOLOGIA}

A metodologia de pesquisa foi iniciada através do lançamento do projeto estadunidense Data Dividend Project, o qual busca principalmente o pagamento de dividendos para moradores do estado da Califórnia após a promulgação do CCPA: Califórnia Consumer Protection Act, legislação de proteção de dados bastante similar à LGPD brasileira e a GDPR europeia. Levanta-se os pontos mencionados pelo projeto norte americano e busca analisar os balanços das principais empresas para realizar uma estimativa realista de implementação do pagamento de dividendos para a população brasileira. Portanto, trata-se de uma pesquisa tipológica a maneira que lista os principais usos de dados digitais na indústria para faturamento e funcionalista ao realizar estimativas ao cenário brasileiro com os dados analisados.

\section{DISCUSSÃO TEÓRICA}

\section{Dados, Metadados e Big Data}

Qualquer informação criada em um ambiente virtual é considerada um dado. Qualquer informação mesmo. Uma anotação feita no aplicativo de celular ao invés de anotado em um papel com uma caneta já é um novo dado. E em um mundo amplamente conectado como o de hoje, as informações virtuais são criadas em um intenso volume.

Segundo Hilbert et al. (2011), em 2003 pela primeira vez os humanos possuíam mais informação registrada de maneira virtual do que o registro físico, analógico, utilizado normalmente durante milhares de anos de evolução da espécie. Significa, portanto, que a partir de 2003, os humanos possuíam uma quantidade maior de dados virtuais, com textos, fotos e aplicações nos computadores, do que cartas, músicas, livros por toda a história desde seu nascimento.

Conforme Kim et al. (2014) em 2014 foi registrado que quase 90\% dos dados do mundo foram gerados nos últimos dois anos daquele período, com uma produção de cerca de 2,5 quintilhões de bytes por dia, através de mídias como mensagens, vídeos, podcasts, músicas, fotos e publicações em redes sociais. Não apenas essas interações e conteúdos digitais são passíveis da classificação registros de dados, mas basicamente qualquer interação registrada em um sistema também é, por exemplo exames médicos registrados em uma plataforma digital, sistemas judiciais, registros em cartório, basicamente toda nova informação produzida atualmente é classificada como dado.

A compilação, agrupamento e organização de todos esses dados é denominado como Big Data, uma classificação que pode ser simplificada com três critérios: Volume, velocidade e variedade de dados. Volume por se tratar de uma grande quantidade de dados. Velocidade, pois, a transmissão dos dados ocorre de maneira cada vez mais rápida. Variedade afinal os dados são gerados em diversos formatos e por diversas fontes. Estes três 'V's que definem o Big Data mais tarde podem ser combinados e analisados para gerar um quarto V, de 'Valor' potencial de mercado através da análise desse agrupamento de informações. 
Isso leva a um outro conceito chamado de Metadados ou Metadata, o que significa a informação sobre os dados (the data about the data). Com a quantidade exponencial de informação geradas a cada dia, o mero fluxo de informação não é suficiente para possuir algum valor se apenas armazenado, é necessária uma extensiva análise de classificação das informações geradas para absorver oportunidades comerciais através da leitura desses dados. Trata-se de uma análise para identificar as pessoas e seus comportamentos, potenciais consumidores, e o que eles fazem. Identificar padrões e traços que permitam catalogar essa informação a um grupo e mais tarde direcionar produtos ou anúncios específicos com uma perfilação desses usuários.

Toda informação gerada possui um potencial de mercado. Acordar de manhã com o despertador, pegar o celular e se locomover até a academia e após o treino trocar mensagens com sua esposa, que te alerta para comprar leite no retorno para a casa, parece uma simples atividade de rotina sem nenhum valor para o mundo exterior, mas umas pessoas com esses hábitos comuns podem revelar muitas informações para diversas empresas. Com o despertador às 6 horas da manhã sua fabricante do celular possui a informação de você acorda cedo e possivelmente não dorme muito tarde. No caminho para a academia seu aplicativo de GPS pode ter registrado o trajeto e destino e identificado, portanto, uma pessoa com hábitos mais saudáveis que frequenta academia. Com a troca de mensagens, se a esposa alerta para a compra de um leite com baixa lactose, o serviço de aplicativos pode detém a informação de alguém da casa com intolerância ao leite comum. Dessa forma, uma análise e adequação de perfil pode sugerir anúncios de uma nova marca de leites com baixa lactose em vídeos assistidos antes das 10 da noite, presumindo que o usuário estaria em um momento fora do turno de suas atividades profissionais.

Muitas empresas estão a todo momento coletando dados triviais, e que para muitos são sem importância. E de alguma maneira, ainda que anonimamente, essas empresas estão registrando um perfil de traços característicos e habituais para possíveis fins comerciais no futuro. Qualquer usuário que tenha baixado um aplicativo no celular, ou utilizado um serviço online, e que tenha clicado no botão de "eu concordo" após um longo texto que ninguém lê, muito provavelmente teve de alguma maneira os dados coletados durante o uso dessas aplicações.

\section{Empresas apoiadas na análise de dados}

Em 2018 as empresas mais valiosas, valiosas dos Estados Unidos eram Apple, Amazon, Alphabet, Microsoft e Facebook. Juntas, as cinco companhias representavam quase $70 \%$ de todo o valor das 10 empresas mais valiosas do país. A China, segunda maior economia mundial, também segue a tendência, e suas duas maiores, maiores empresas, Alibaba e Tencent, representam quase $40 \%$ do valor total das 10 mais valiosas empresas do país. O que todas essas empresas possuem em comum é o combustível de dados que de alguma maneira abastece as operações e direciona decisões das companhias.

Microsoft, a terceira maior companhia aberta do mundo possui diversas fontes de informação e coleta de dados. A empresa é responsável por diversos serviços, entre eles, Azure, Bing, Dynamics 365, LinkedIn, Microsoft Teams, Office 365, OneDrive, Outlook, SharePoint Online, Skype, Xbox. Com um valor de 
mercado de 1,2 trilhão de dólares, a empresa possui a monetização de dados como uma fonte confiável de receita. Conforme o Relatório Anual da Microsoft (2019) o Bing Ads, seu serviço de propaganda, foi responsável por quase 800 milhões de dólares em faturamento no ano. Além disso, o Linkedln, rede social com mais de 400 milhões de usuários é toda dependente na análise de dados dos utilizadores para funcionamento e aprimoramento da plataforma, rastreando os cliques e interações dos usuários durante todo o uso. Não apenas isso, a rede social conta com quase $30 \%$ de sua receita através de anúncios direcionados pelo mapeamento dos traços dos usuários. A Microsoft é uma verdadeira máquina de extração, coleta e registro de dados através de suas plataformas, e possui até mesmo um serviço de base de dados e consultoria para empresas em como utilizar as informações corretamente, através do Analytics Platform System. Não para por aí, seu sistema operacional, o Windows 10, deliberadamente monitora todas as atividades dos usuários, tanto online, como também off-line, e de acordo com Marr (2016) a companhia registra até mesmo informações sobre arquivos salvos no disco rígido. Todas as diversas fontes de dados da Microsoft são fundamentais para as atividades operacionais da empresa, tanto direta como indiretamente, sendo evidente na análise de caso da Microsoft como dados realmente se comportam como petróleo nas mãos da companhia.

A Alphabet, quarta maior companhia aberta dos Estados Unidos, com valor de mercado acima de 920 bilhões de dólares, possui um valor direto dependente em dados ainda maior do que a Microsoft. Alphabet, de maneira simplificada, é um rebranding do Google, portanto o Google passou a ser um ativo dentro do guarda-chuva dessa empresa nomeada de Alphabet. Dentre os portfólios de produtos e serviços encontra-se o sistema operacional Android, o Google buscador, Chrome, Gmail, Google Drive, Google Maps, Google Play e o YouTube. A Alphabet (2019) afirma em seu Relatório Anual que cada um desses serviços citados possui mais de um bilhão de usuários ativos todo mês. A grande fonte de faturamento da companhia é através de publicidade, e, portanto, monitora constantemente os usuários para atribuir com efetividade seus direcionamentos publicitários e adequadamente vendê-los como campanhas produtivas. Engana-se quem achava que o Google se tratava de um simples buscador de informações na internet, o Google, ou Alphabet, pode ser considerada como uma empresa de inteligência artificial, que identifica os traços comportamentais dessas simples buscas dos usuários e transforma em dados relevantes que podem ser utilizados de diversas maneiras. Em linhas mais obscuras, a companhia também foi acusada de extrair dados de localização dos usuários de seu sistema e aplicativos e revender essas informações para planejadores urbanos.

A Amazon, gigante varejista, e atualmente maior companhia americana, possui uma acentuada integração de coleta e análise de dados para melhorar cada vez mais a performance de seus resultados financeiros. Com aplicação de collaborative filtering engine (CFE) para analisar o histórico do consumidor e recomendar novos produtos, a empresa possui uma das ferramentas de recomendação mais versáteis do mercado, conforme Marr (2016), com a teoria de quanto mais a empresa conhece, mais ela será capaz de prever o que você deseja comprar.

O Facebook, com quase 700 bilhões em valor de mercado, não é diferente, e uma das empresas mais 
dependentes nos dados de seus usuários. A empresa engloba a rede social de seu nome, os aplicativos Instagram, Messenger e WhatsApp, e a empresa Oculus voltada para realidade virtual. De seus 70,7 bilhões em faturamento em 2019, 69,66 bilhões foram oriundas de publicidade, virtualmente toda a receita da companhia, 99\% são através da publicidade direcionada adequadamente a seus usuários, coletando dados através da atividade em seus aplicativos e redes sociais.

O Facebook afirma em seu Relatório Anual que:

Nós geramos substancialmente toda nossa receita através da venda de canais de publicidade para profissionais de marketing. Nossos anúncios permitem os publicitários alcançar pessoas baseados em uma variedade de fatores como idade, gênero, localização, interesses e comportamentos.

A Apple, segunda maior empresa aberta do mundo com valor de mercado de quase 1,3 trilhão, aparenta por outro lado seguir um caminho diferente e não depender tanto de dados para uma monetização direta. A empresa possui através de seus executivos um discurso pró-privacidade e estimula medidas que resguardem os dados dos usuários. Contudo não é possível fugir de alguma análise de informações. Para a própria produção de seus produtos a empresa é de alguma forma dependente em dados para direcionar novos recursos e inovações para iPhones, iPads, Macs e Apple Watches, utilizando das informações dos usuários para endereçar efetivamente as funções que vão melhorar a experiência do usuário ou torná-la mais confortável, conforme Marr (2016). Além disso, para treinar e melhorar a Siri, a assistente virtual da empresa, a Apple mantém armazenados dados de voz de seus consumidores por até dois anos para servirem de estudo e melhorar a assistente. De outras maneiras, a Apple também utiliza os dados de batimentos cardíacos dos usuários do Apple Watch para, de acordo com a companhia e Perez (2019), ajudar de alguma forma a saúde dos seus consumidores, embora pareça a primeiro momento uma atitude altruísta da empresa, a estigma de que seus produtos possam contribuir com a saúde de alguma maneira também acrescentam marketing positivo e pode melhorar ainda mais a performance de vendas dos produtos.

A verdade é que quase não há hoje empresas que de alguma forma não utilizem dados dos seus usuários para monetizarem ou aprimorarem as atividades de alguma maneira. A lista é imensa e até mesmo startups, pequenas empresas e estágios iniciais, estão dependentes do uso de dados para elaboração de sua tecnologia, plano de negócios e estudos assertivos de mercado.

A análise de dados permeará cada vez mais todas as atividades disponíveis, desde as mais simples às mais robustas, tecnológicas ou não, e se tornarão um aspecto importante das operações

\section{O mercado secundário das Data Brokers}

O lucro através dos dados dos usuários não se limita à utilização pelas empresas, existe também uma indústria bilionária que utiliza constantemente a prática de revenda das informações dos usuários para diversos serviços e empresas, através das corretoras de dados. Este tipo de prática não é novo, e pode ser datado há algumas décadas, mas a nova escala e proporção com a transação dos dados é um fator alarmante e que precisa ser cuidado com atenção.

Na Europa e nos Estados Unidos esse tipo de prática de venda de informações de terceiros já é 
considerado rotineira na indústria de crédito. Devido ao grande volume, velocidade e variedade das informações geradas através das ferramentas atuais (os três 'V's do Big Data), a indústria de corretagem de dados tomou proporções escandalosas.

De acordo com a agência Americana FTC (2012), Federal Trade Comission, a definição, a definição de corretoras de dados, ou também Data Brokers, são empresas que coletam informações pessoas de consumidores através de fontes públicas ou privadas e depois revende as informações para outras empresas. Essas corretoras, em 2012, foram responsáveis por um faturamento anual de 156 bilhões de dólares, conforme relatório do Senado dos Estados Unidos através da prática de coleta e revenda de dados.

Entre as empresas mais conhecidas dessa indústria, é possível citar a Acxiom, Datalogix, LexisNexis Risk Solutions, e a Epsilon, esta última que sozinha faturou em 2019 mais de 1,9 bilhão de dólares com a coleta de dados de mais de 160 milhões de usuários. A Acxiom (2013) segundo seu Relatório Anual detém informações de mais de 700 milhões de usuários no mundo todo. A Datalogix afirma possuir dados de todas as residências dos Estados Unidos, além de nomes de consumidores, endereços de e-mail e histórico de compras de diversos consumidores nos Estados Unidos. Um relatório no Senado dos Estados Unidos explicitou essas e diversas outras práticas que expões os dados de milhares de usuários, de acordo com estimativas do relatório, mais de 250 mil websites na internet explicitamente declaram em sua política de privacidade e coletam dados dos usuários e compartilham com outras empresas.

Os compradores de dados são os mais variados possíveis, e vão desde instituições financeiras, à rede de hotéis, joalherias e outras corretoras, a lista de clientes apenas da Acxiom incluem: 47 clientes da Fortune 100, 12 das 15 maiores emissoras de cartão de crédito, 7 dos 10 maiores bandos de varejo, 8 das 10 maiores empresas de telecomunicação e mídia, 7 das 10 maiores varejistas, 11 das 14 maiores fabricantes de automóveis, 6 das 10 maiores empresas de corretagem, 3 das 10 maiores empresas da indústria farmacêutica, 5 das 10 maiores empresas de seguro de vida e plano de saúde, 9 das 10 maiores seguradoras de propriedade e acidentes, 8 das 10 maiores empresas de hospedagem, 2 das 3 maiores empresas de jogos, 3 das 5 maiores empresas de aéreas dos Estados Unidos, e 6 dos 10 maiores hotéis dos Estados Unidos.

Esse vasto portfólio de clientes de uma única empresa se converte em milionárias transações alimentadas unicamente pelos dados de usuários coletados em diversos serviços. As práticas de corretoras de dados estão presentes em muitos locais, inclusive em empresas não convencionais de tecnologia, um exemplo é a Clever, empresa que coleta dados de mais de 44 mil escolas de educação básica americanas para auxiliar professores a avaliarem performances dos alunos.

No fim, todo dado coletado pode ser utilizado de alguma maneira e monetizado pelas empresas que os detém, afinal a aplicação prática de teorias da economia comportamental tendem a ser cada vez mais aplicadas para potencializar as vendas, faturamento e performance das empresas, uma vez que a vasta quantidade e qualidade de dados alcança novos patamares a cada dia.

\section{Economia Comportamental}

Com a vastidão de pessoas acessando a internet atualmente e criando diversos registros de seus 
traços comportamentais em simples tarefas cotidianas e informais, as companhias com a disponibilidade de tantas informações podem utilizar dos fatores sociais e psicológicos para mais assertivamente melhorarem suas vendas ou produtos. Como visto no tópico anteriormente, a Amazon analisa o histórico dos consumidores para recomendar indicações, a Microsoft obtém domínio de todo dado passível de seu acesso, Google e Facebook identificam grupos de usuários para oportunidades de anúncios, os dados permitem um acesso íntimo aos possíveis interesses dos usuários para lhes ofertar produtos ou serviços, aplicando o campo de economia e finanças comportamentais para geração de receita em companhias das mais diversas áreas.

O professor Shefrin et al. (2018) da Universidade de Santa Clara e autor do livro "Behavioral Risk Management" define a economia comportamental como "o estudo de como a psicologia impacta o comportamento econômico através de motivações e julgamento, a maneira como interpretamos dados e depois utilizamos os dados para tomar decisões". Com o desenvolvimento de inteligências artificiais e machine learning é possível analisar uma grande quantidade de dados para prever o comportamento dos usuários, e dessa forma basicamente toda a indústria atual de uma maneira ou de outra utiliza de informações, algumas mais diretas ou indiretamente para planejar o desenvolvimento dos negócios. Com o crescimento exacerbado da produção de dados no mundo atual, as informações digitais passaram a se tornar um fundamento intrínseco de toda companhia moderna. Segundo Rieke et al. (2016):

As técnicas que são usadas para identificar e combinar o comportamento de indivíduos específicos através de diferentes canais estão se tornando mais sofisticadas (...) Corretoras de dados podem combinar dados online e off-line para produzir uma grande variedade de previsões quanto aos comportamentos dos consumidores e seus possíveis interesses. Redes de anúncios podem então agir por dessas previsões para segmentar donos de carros de luxo online. Ou uma corretora de dados pode ajudar uma empresa a analisar os dados dos seus atuais clientes para identificar novos consumidores com localização semelhante. Grandes plataformas online como Facebook, Twitter ou Google trabalham de mãos dados com corretoras como a Acxiom, Datalogix, e Epsilon para direcionar propagandas e otimizar a efetividade dos anúncios online. Corretoras de dados permitem que anunciantes utilizam o histórico de compras de consumidores como também outros comportamentos online e offline para direcionar anúncios. (...) utilizando tanto dados online como off-line, Facebook e Twitter ajudam anunciantes a criar audiências similares, o que permite anunciantes mostrarem anúncios para pessoas semelhantes a seus clientes atuais.

Embora algumas pessoas acreditem estar fazendo o uso de plataformas e redes sociais de maneira inteiramente gratuita, o custo na verdade está escondido através da grande capacidade de vigilância dessas empresas para identificar os traços comportamentais dos usuários e conseguir criar valor com sua monetização, conseguindo comercializar em cima de pacotes de informações de localizações, interesses e relacionamentos. Através da análise desses padrões psicológicos e comportamentais coletados dos usuários, anunciantes podem mais assertivamente direcionar seus anúncios e empresas podem adequar seus planos de negócios para maximizar a carteira de clientes.

A indústria farmacêutica também vem se direcionando para utilização de Big Data para aumentar o crescimento das companhias. As empresas farmacêuticas com a ajuda de inteligência artificial podem produzir previsões sobre os consumidores e identificar oportunidades de mercado à custos baixíssimos. Oportunidades que podem ser exploradas para pesquisar novos campos ou até mesmo se defender de competição, tudo isso possibilitado com o combustível de dados digitais injetados na indústria. 
Definitivamente os dados digitais mudaram completamente a maneira como as indústrias operacionalizam suas atividades. Seja uma grande titã tecnológica ou companhias convencionais de outros setores, a utilização de dados é constante para diversas finalidades. Embora os dados sejam grandes potencializadores de negócios, apenas atualmente é que está ocorrendo uma comoção mundial para regularização legislativa sobre seus usos. Tanto para preservação de privacidade ou titularidade dos dados digitais, a partir de 2020 as legislações podem alterar a maneira como a indústria e os usuários lidam com as informações virtuais.

\section{Regramento Normativo Quanto ao Uso de Dados}

Embora os dados digitais estejam possibilitando uma revolução há uma década, ainda recentemente os órgãos legislativos do mundo todo eram omissos quanto ao tema, e só há pouquíssimo tempo alguns governos começaram a se movimentar para regular o acesso de empresas aos dados gerados durante o uso de serviços e aplicativos na internet.

As companhias em sua busca pelo aprimoramento constante de seu portfólio de dados começaram a cada vez mais a buscar dados mais íntimos para individualização de um público e torná-los alvo de publicidades direcionadas cada vez mais efetivas. Dessa forma, as conversas iniciais quanto à coleta de dados virtuais e atuação do Estado nestas relações se engendraram em um ambiente protetivo, no qual se conceberam ideias que contribuíssem para blindagem dos usuários de serem expostos e terem os dados rodando empresas do mundo todo. Claro que neste ponto inicia-se um questionamento sensível, pois não poderiam os Estados simplesmente coibirem completamente o acesso à coleta e análise de dados, uma vez que dificilmente conseguiriam frear uma trilionária indústria tecnológica que nasceu e continua crescendo em função disso. Deveria, portanto, ponderar as tratativas éticas de coleta e análise de dados e apenas impor barreiras a certos limites, e não proibir a prática de maneira abrupta.

O primeiro debate sobre o tema se iniciou na União Europeia, que já possui a tendência de assumir a vanguarda legislativa de diversos temas que versam sobre temas ainda inexplorados. Nasceu, portanto, 0 texto base do GDPR (2016), Regulamento Geral sobre a Proteção de Dados, em português, que passou a ter vigência em 2018 e serviu de norte para países do mundo todo seguirem as regras que versam sobre o tema. Em suma, a GDPR Europeia cria direitos para os usuários de internet e vincula obrigações para as companhias, legisla sobre a classificação e coleta de vestígios virtuais classificando alguns dados como pessoais e, portanto, obriga os portadores de dados digitais a coletarem o consentimento dos usuários para uso comercial das informações e gerar relatórios de transparência. A lei também garante aos usuários direito de não serem discriminados através de propagandas direcionadas e expressa a possibilidade de que companhias deletem informações dos usuários quando assim forem solicitadas.

A indústria agiu com cuidado, e grandes empresas já declararam em seus relatórios financeiros que a lei pode impactar negativamente a efetividade de seus anúncios e a maneira como catalogam os usuários e seus traços comportamentais, mas também já estão tomando medidas para agir em total compliance com as novas legislações e não ter problemas no futuro. Segundo o Facebook em seu relatório anual: 
Nós contamos com sinais de dados de atividades de usuários em websites e serviços que não controles para entregarmos relevantes e efetivos anúncios para nossos usuários. Nossa receita é dependente de direcionamento e ferramentas de medição que incorporam esses sinais, e quaisquer mudanças na nossa capacidade de usar esses sinais afetará adversamente nosso negócio. Por exemplo, mudanças legislativas e regulatórias, como a GDPR e CCPA, já impactaram, e esperamos que continuarão impactando nossa capacidade de utilizar esses sinais em nossos produtos de propaganda. (...) Esses acontecimentos limitaram nossa capacidade de direcionar e medir a eficácia dos anúncios em nossa plataforma, e em qualquer perda adicional de tais sinais no futuro afetará adversamente nossa capacidade de direcionamento e medição e impactando negativamente nossa receita com publicidades.

Outros países já agiram para aplicar uma legislação similar em suas jurisdições, entre eles, um autor cita a Índia como um dos vanguardistas. Além disso, o Japão, Coreia do Sul, Estados Unidos, e principalmente e Brasil se moveram para legislar para seus usuários.

\section{Lei Geral de Proteção de Dados}

Já em debate desde 2018, a LGPD (2018), Lei Geral de Proteção de Dados, entrou em vigência em todo território nacional a partir de agosto de 2020. Contudo, as empresas não esperaram até o prazo limite para se adequarem ao novo regramento, e desde 2019 os brasileiros notaram uma enxurrada de e-mails esclarecendo novos termos de uso para plataformas e aplicativos em compliance com a nova legislação.

A Lei brasileira admite em seu artigo 17 que toda pessoa natural é titular de seus dados digitais, e pode, portanto, concomitantemente ao artigo 18, exigir a transparência das empresas que portam seus dados, corrigir dados errados ou incompletos, ou até eliminar todos os dados em posse de alguma empresa, junto a diversos outros direitos listados nos incisos do artigo.

Em sintonia com a lei de proteção de dados europeia, a legislação brasileira possuía a ideia central de garantir a privacidade dos usuários e atribui a seus cidadãos diversos direitos perante as empresas. Contudo, nenhum desses efeitos é automático. O usuário que deseja relatório de seus dados, ou proibir a coleta precisa comunicar a empresa e esperar a atuação desta para efetivação dos efeitos.

\section{CCPA}

Introduzida no estado da Califórnia, nos Estados Unidos, a Califórnia Consumer Privacy Act (2020) de maneira geral vislumbra o mesmo pacote de direitos para os consumidores de produtos e serviços digitais: O direito de saber quais informações são coletadas, compartilhadas e vendidas, o direito de deletar informações em posse das companhias, o direito de não serem discriminados em preços e o direito de proibirem a venda de suas informações pessoais para terceiros.

Como o Estados Unidos é o país com maior volume de faturamento através do uso de dados para anúncios e otimização da vastidão de empresas abastecidas pelos dados sediadas no país, através da CCPA que garante direitos aos usuários pela titularidade dos seus dados, os californianos podem simplesmente negociar com as companhias uma remuneração pela utilização de seus dados.

Outros estados americanos já estão se movimentando para aprovarem legislações similares. Maine e Nevada também já aprovaram suas leis de proteção de dados, mas ainda não entraram em vigência. Os 
estados de Arizona, Hawaii, Illinois, Maryland, New Hampshire, New Jersey, New York, South Carolina e Texas iniciaram o debate em suas câmaras legislativas. Se todos esses estados aprovarem suas legislações, o que provavelmente vai acontecer, e os usuários começarem a se unir para reivindicação de seus direitos, o escopo de companhias tecnológicas e corretoras de dados pode mudar fundamentalmente.

\section{Remuneração pela utilização dos dados pessoais}

Através das novas legislações de proteção de dados, os usuários agora podem optar por restringirem completamente o acesso às suas informações e proibir a coleta de dados, comportamentos e valiosas informações pessoais pelas companhias. Se umas grandes massas de usuários resolvessem assumir essa postura protecionistas grande parte da economia futura poderia se comprometer. Essa possibilidade, entretanto, parece pouco provável. Um exemplo foi o aplicativo russo FaceApp, que se popularizou em 2017 pelo efeito de envelhecimento em fotos, mas que coletava diversos dados pessoais em segundo plano, e após exposição dos possíveis danos à privacidade o aplicativo foi removido das lojas. Entretanto o FaceApp retornou em 2019 e o aplicativo já se popularizou novamente antes mesmo das pessoas checarem a segurança dessa nova versão.

$\mathrm{Na}$ realidade, as pessoas sequer entendem completamente as ideias da privacidade digital e os problemas que o tema envolve, então não podem de maneira assertiva tomar alguma decisão acerca de seus dados. Um estudo realizado pela Pew Research, conduzido por Auxier et al. (2019) mostrou que o público americano não compreende sequer assuntos básicos relativos ao tema, e $75 \%$ da população dos Estados Unidos acreditavam que a janela em modo anônimo dos navegadores protegia os vestígios dos usuários que utilizavam a ferramenta. Além disso, mais de $50 \%$ não entendem que os termos de privacidade de sites, aplicativos, serviços e redes sociais são uma espécie de contrato entre aquele serviço e o usuário.

Embora a população americana não compreenda de maneira correta como funciona a privacidade digital, os usuários possuem sim alguma preocupação com o uso de dados coletados pelo governo e por companhias privadas, e cerca de $80 \%$ demonstraram se importar em como as redes sociais e anunciantes utilizam as informações coletadas. Entretanto, a facilidade com se baixa um aplicativo em comparação a burocracia para solicitar a transparência de seus dados pode afastar muitas pessoas de realmente irem atrás de seus direitos e não se importarem com uma restrição total com a coleta de suas informações.

Analisando todo o cenário, há uma solução que se apresenta adequada para essa temática, ao invés dos usuários proibirem o uso de seus dados, eles podem ser pagos por eles. Neste sentido, companhias não teriam problemas em seguir com suas operações e os usuários além de entrarem em protocolos de relatórios constantes de transparência, seriam devidamente remunerados por prestarem o combustível de grande parte da economia de hoje e do futuro.

A ideia de remuneração pelo uso dos dados dos usuários surge muito naturalmente após um pouco de estudo sobre o mercado digital. Toda a infraestrutura deste mercado é construída em cima dos dados coletados e a perspectiva futura dessa indústria digital se mantém intrinsicamente ligada a estes fundamentos. 
Como visto acima, os dados digitais realmente se portam como commodities da economia atual e são o combustível de diversas empresas. Desde as grandes titãs tecnológicas, à startups, hotelaria, farmácias, joalherias e um mercado secundário de corretoras de dados, as informações pessoais dos usuários são fundamentais para o funcionamento ou aprimoramento das atividades empresariais.

Com as informações e grande base de dados sendo cada vez mais imprescindíveis para treinamento de inteligências artificiais, estudos de oportunidades de mercado e venda de anúncios, é compreensível que os usuários busquem uma remuneração pela cessão de titularidade de seus dados para as companhias. Afinal, com as novas legislações as pessoas podem simplesmente restringir a coleta e deletar informações que já estão em posse das companhias, estão seria preferível, por ambas as partes, que seja mantido o fluxo atual de informações, mas que agora o usuário seja então compensado pela coleta e uso de seus dados.

Não se trata de uma simples venda, a ideia de remuneração pelos dados deve ser entendida como uma permissão para exploração contínua das informações, como uma espécie de royalties pelos dados. Tratando os dados digitais em uma estrutura jurídica de propriedade intelectual, com uma remuneração constante pelo uso.

A linha deste raciocínio além de fazer sentido econômico, é muito debatida entre técnicos da indústria digital como um fundamento ético e de dignidade a favor da propriedade dos dados digitais. A alcunha de Data Dignity, ou dignidade de dados pela tradução livre, é um termo criado por Lanier et al. (2018) no um artigo da Harvard Business School chamado 'A Blueprint for a Better Digital Society'. Trata-se de um conceito para devolver o poder aos usuários e entregar a eles a decisão de o que fazer com seus dados, seja preservá-los ou vendê-los, mas através de um processo claro e transparente, que permite a liberdade individual de cada usuário sobre o destino de suas informações pessoais.

\section{Dividendos sobre dados}

Utilizando da estrutura jurídica de propriedade intelectual para aplicar aos dados digitais, surge a ideia de uma remuneração periódica pela exploração de dados. Seria, portanto, um pagamento de dividendos pelo uso das informações virtuais. Com a concepção de dados digitais como uma commodity perpétua e perene na indústria 4.0, e que devem realmente substituir o petróleo como importância e influência de mercado, os dados devem ser tratados como um ativo.

O futurista e filósofo Jaron Lenier, co-autor do artigo citado anteriormente 'A Blueprint for a Better Digital Society' prevê que as transações transparentes de dados com a permissão dos próprios usuários, dados como um ativo, podem desfrutar de grande valorização, permitindo grandes avanços na economia digital, com as pessoas intencionalmente ajudando os serviços automatizados a funcionarem de maneira melhor, uma vez que agora elas seriam pagas por isso, defendendo que a tese de Seis Sigma, popularizada no Japão, possa ser aplicada no mundo digital. Lanier em uma entrevista para Andrew Yang afirmou que quando pessoas estão trabalhando em algo se tornam consciente sobre como o que elas estão fazendo está contribuindo para a qualidade para a sociedade, essas pessoas passam a ter orgulho disso ao invés de serem tratados como robôs. Foi a aplicação dessa filosofia que fez o Japão possuir melhores linhas de produção 
industriais. Se a essa filosofia do Seis Sigma for aplicada no vale do silício, Lanier acredita que as pessoas ficariam motivadas para tornar seus dados mais produtivos e ganhar um poder de decisão sobre o que o algoritmo deveria fazer com os dados. Este é um dos fundamentos éticos para a dignidade de dados também citada anteriormente, tornar as pessoas participantes ativos de todos os procedimentos para tornar seus dados ainda mais úteis, uma vez que aguardam uma remuneração por eles.

Surgiu, portanto, através da oportunidade da nova legislação quanto a proteção de dados no estado americano da Califórnia, um grupo organizado que idealizou uma proposta para que os usuários recebam dividendos pela constante exploração das informações. O Data Dividend Project é liderado por Enoch Liang, famoso advogado de propriedade intelectual em San Francisco, e Andrew Yang, candidato das primárias do partido democrata para as eleições presidenciais nos Estados Unidos em 2020.

O projeto advoga que com tantas empresas lucrando com os dados pessoais de cada cidadão, estes também deveriam ter direito sobre a remuneração por tornar toda uma indústria possível, e pretende, através de uma ação coletiva, obrigar as companhias a pagar dividendos mensais ou anuais para os usuários.

No tratamento de dados como uma commodity utilizada como combustível para diversos setores e empresas, os legítimos donos dos ativos também possuem interesse em ampliar a economia digital e aumentar sua qualidade, uma vez que quanto maior o alcance do uso dos dados, maior será a remuneração esperada, e o projeto de Liang e Yang, se conseguirem efetivamente que as empresas realizem o pagamento de dividendos aos usuários, poderá, enfim, revolucionar a economia do futuro.

Yang quando em campanha presidencial pelas primárias do partido democrata foi um ávido defensor do conceito de renda básica universal, e acredita que os dividendos pelos dados digitais podem enfim concretizar a ideia da renda para todos os cidadãos. Com grande parte da população conectada ao mundo digital, as pessoas podem receber pagamentos apenas pelo exercício comum de utilizarem a internet e gerarem pacotes de dados.

Uma vez que os planos de negócio e inteligências artificiais são moldados aos gostos dos usuários, os novos dados nunca deixarão de se tornar relevantes. Como a sociedade é dinâmica e passa por constantes alterações, as empresas sempre vão necessitar dos dados mais recentes para se adaptarem e entenderem como se portam os mercados a partir dos novos gostos dos usuários. Isso garante com que o pagamento de dividendos também seja constante, e não deverá cessar quando uma empresa achar que já tem dados suficientes, pois com o constante fluxo de informações, novos dados sempre serão considerados valiosos.

\section{Aplicação no Brasil}

Mesmo que os Estados Unidos e Canadá possuam um mercado dominante para as companhias, o Brasil não fica muito atrás e demonstra ser um player relevante no mercado digital como um todo. De acordo com dados do Brazil Digital Report, de Calicchio et al. (2019), o Brasil está entre os países que mais consomem internet no mundo, com uma média de mais de 9 horas por dia conectados, com brasileiros gastando em média 41\% mais tempo em mídias sociais que os americanos.

Com mais de 69 milhões de visualizações por mês, os brasileiros são a segunda nação que mais 
utilizam o YouTube no mundo. O Netflix, com 7,5 milhões de assinantes brasileiros já é maior que a NET, maior provedora de TV a cabo do país. Com mais de 130 milhões de usuários no Facebook, o Brasil é o terceiro país que mais utiliza a rede social. E com 120 milhões de usuários, os brasileiros são o maior público do WhatsApp, com 91\% de penetração entre usuários de internet do país. Os brasileiros são o segundo maior público do Instagram, com mais de 50 milhões de usuários. É o 2o país com mais usuários do Pinterest, terceira maior base do Linkedln e sexto maior público do Twitter. O Brasil é o único país além dos Estados Unidos a possuir um ecossistema de infraestrutura completa do Google.

Ainda assim, apenas $36 \%$ do investimento em anúncios está concentrado no mercado digital brasileiro. Portanto há um grande espaço para crescimento. Se seguir a tendência dos Estados Unidos, em pouco tempo o investimento com publicidade digital ultrapassará os gastos com a televisão, que desde 2015 possui uma receita quase $20 \%$ maior que a publicidade televisiva.

Justifica-se, portanto, que os brasileiros também adotem a política de remuneração de seus usuários pela grande capacidade de geração de dados. Embora este movimento de dividendos pelo uso de dados tenha se iniciado nos Estados Unidos, a legislação da Califórnia, que liderou toda a dinâmica, não é muito diferente da lei de proteção de dados brasileira ou Europeia. Todas essas legislações simplesmente protegem os usuários da extração predativa. Não seria necessária nenhuma alteração à Lei 13.709/18, Lei Geral de Proteção de Dados para buscar a compensação monetária pelo uso dos dados de usuários brasileiros pelas companhias.

Seria prudente aguardar pelo desenvolvimento do Data Dividend Project americano, estudar e aprender com seus erros e acertos para dimensionar a viabilidade concreta de aplicação em território brasileiro. Não está claro ao certo qual deve ser efetivamente a remuneração recebida pelos usuários, já que este pagamento de dividendos também é passível de negociação com as empresas, mas é possível estimar quais seriam os proventos recebidos por brasileiros em aplicação afirmativa da política de dividendos para os usuários. É razoável uma projeção de alguns cenários para estabelecer como base o pagamento pelo uso de dados.

\section{Projeções}

O pagamento de dividendos deve ser encarado como um custo de receita. Pois através do compartilhamento voluntários dos dados os usuários permitem o desenvolvimento de indústrias e negócios que anteriormente, sem os dados, teriam dificuldade de ampliarem o faturamento e aproveitarem oportunidades de negócios.

O relatório Notes From The Al Frontier Insights From Hundreds of Use Cases, de Chui et al. (2018), revela um gigantesco potencial em todos os setores através de aplicação de análise de dados nos negócios. O estudo aponta que apenas com a integração de Inteligência Artificial as empresas poderão perceber um potencial de 3,5 a 5,8 trilhões de dólares em geração de valor anualmente, e até 9,5 a 15,4 trilhões de dólares por ano agregando também outras técnicas de análises de dados nos procedimentos empresariais.

Não se trata apenas das big techs, este impacto trilionário nas receitas seria observado, por exemplo, 
em setores como: Agricultura, automotivo, bancário, químico, petróleo e gás, farmacêuticos, transporte e logística e telecomunicação. Os dados dos usuários, portanto, potencializariam trilhões em ganhos para todos os setores possíveis com a integração de análise de seus dados.

É possível idealizar alguns cenários para prever os eventuais dividendos recebidos pelos usuários. 0 Facebook é uma das poucas empresas a demonstrar em seus relatórios o efetivo ARPU (Receita média por usuário) de suas plataformas. No último trimestre de 2019 , a empresa estimou quase $\$ 40,4$ dólares em receita por usuário dos Estados Unidos e Canadá e \$2,45 dólares por usuário do resto do mundo, isso dá uma taxa equivalente a 0,04\% em receita por milhão para usuários fora da América do Norte.

Para a projeção o presente artigo, considerou-se uma taxa de crescimento necessária para que a receita por usuário brasileira, ou resto do mundo, alcance o ARPU americano, que atualmente é de 0,13\% por receita por milhão, portanto um CAGR de 12\% em 10 anos.

Além disso, a taxa de conversão do dólar para o Real brasileiro utilizou as projeções cambiais do relatório Focus do Banco Central, e assim US\$1 $=\mathrm{R} \$ 5,20$ em 2020, $R \$ 5,00$ em 2021, e $R \$ 4,80$ para 2022 e seguintes anos.

Criou-se, portanto, 4 cenários, nos quais o valor base anual é de 3,5; 5,8; 9,5 e 15,4 trilhões de dólares anuais e duas variações em cada com um custo de receita a taxas de 5 e $10 \%$. Calcula-se o pagamento de 0,04\% em cima dessas projeções de receita e aplica-se 5 ou 10\% em custo de receita para pagamento dos usuários, e adicionando um crescimento de $12 \%$ ao ano nos períodos seguintes ao primeiro ano para alcançar o ARPU norte americano. Resultados nas Tabelas 1, 2, 34.

Os valores resultantes de todos os cenários estão longe de concretizarem a ideia de renda básica universal através dos dividendos de dados como sugeriu Andrew Yang. Contudo são valores que podem agregar à vida das pessoas, principalmente em jovens que decidam reservar estes valores pensando em uma perspectiva futura para o montante de dinheiro arrecadado ao longo de 10 anos.

Reforça-se, contudo, que se trata de uma opção dos usuários. A reclusão e proteção à privacidade de dados é um direito garantido pelas novas legislações de proteção de dados, e passa a ser optativa a escolha por permitir ou não a coleta de dados pelas companhias para recebimento dos valores.

Tabela 1

\begin{tabular}{|c|c|c|c|c|c|c|}
\hline \multicolumn{7}{|c|}{ US\$ 3,5 Trilhão } \\
\hline \multicolumn{7}{|c|}{ Ano Monthly Yield } \\
\hline 2020 & US $\$ 5,71$ & US $\$ 68,51$ & $12 \%$ & $R \$ 5,20$ & 356,27 & 712,54 \\
\hline 2021 & US \$ 6,39 & US $\$ 76,73$ & $12 \%$ & $R \$ 5,00$ & 383,67 & 767,35 \\
\hline 2022 & US $\$ 7,16$ & US $\$ 85,94$ & $12 \%$ & $\mathrm{R} \$ 4,80$ & 412,53 & 825,05 \\
\hline 2023 & US $\$ 8,02$ & US \$96,26 & $12 \%$ & $R \$ 4,80$ & 462,03 & 924,06 \\
\hline 2024 & US $\$ 8,98$ & US \$107,81 & $12 \%$ & $R \$ 4,80$ & 517,47 & $1.034,95$ \\
\hline 2025 & US $\$ 10,06$ & US \$120,74 & $12 \%$ & $R \$ 4,80$ & 579,57 & $1.159,14$ \\
\hline 2026 & US $\$ 11,27$ & US $\$ 135,23$ & $12 \%$ & $\mathrm{R} \$ 4,80$ & 649,12 & $1.298,24$ \\
\hline 2027 & US $\$ 12,62$ & US \$151,46 & $12 \%$ & $R \$ 4,80$ & 727,01 & $1.454,03$ \\
\hline 2028 & US \$14,14 & US \$ 169,64 & $12 \%$ & $R \$ 4,80$ & 814,26 & $1.628,51$ \\
\hline 2029 & US $\$ 15,83$ & US \$189,99 & $12 \%$ & $R \$ 4,80$ & 911,97 & $1.823,93$ \\
\hline 2030 & US $\$ 17,73$ & US \$ 212,79 & $12 \%$ & $\mathrm{R} \$ 4,80$ & $1.021,40$ & $2.042,80$ \\
\hline & & & & Acumulado & $\mathrm{R} \$ 6.835,30$ & $\mathrm{R} \$ 13.670,60$ \\
\hline
\end{tabular}


Tabela 2

\begin{tabular}{|c|c|c|c|c|c|c|}
\hline \multicolumn{7}{|c|}{ US\$ 5,8 Trilhão } \\
\hline \multicolumn{7}{|c|}{$\begin{array}{ll}\text { US\$ 5,8 } & \text { Trilhao } \\
\text { Ano } & \text { Monthly Yield }\end{array}$} \\
\hline 2020 & US $\$ 9,46$ & US \$113,54 & $12 \%$ & $\mathrm{R} \$ 5,20$ & 590,39 & $1.180,78$ \\
\hline 2021 & US $\$ 10,60$ & US \$127,16 & $12 \%$ & $\mathrm{R} \$ 5,00$ & 635,80 & $1.271,61$ \\
\hline 2022 & US \$11,87 & US \$ 142,42 & $12 \%$ & $\mathrm{R} \$ 4,80$ & 683,62 & $1.367,23$ \\
\hline 2023 & US $\$ 13,29$ & US \$ 159,51 & $12 \%$ & $\mathrm{R} \$ 4,80$ & 765,65 & $1.531,30$ \\
\hline 2024 & US $\$ 14,89$ & US \$178,65 & $12 \%$ & $R \$ 4,80$ & 857,53 & $1.715,06$ \\
\hline 2025 & US $\$ 16,67$ & US $\$ 200,09$ & $12 \%$ & $\mathrm{R} \$ 4,80$ & 960,43 & $1.920,86$ \\
\hline 2026 & US $\$ 18,68$ & US \$ 224,10 & $12 \%$ & $\mathrm{R} \$ 4,80$ & $1.075,68$ & $2.151,37$ \\
\hline 2027 & US $\$ 20,92$ & US \$ 250,99 & $12 \%$ & $\mathrm{R} \$ 4,80$ & $1.204,77$ & $2.409,53$ \\
\hline 2028 & US $\$ 23,43$ & US \$ 281,11 & $12 \%$ & $\mathrm{R} \$ 4,80$ & $1.349,34$ & $2.698,67$ \\
\hline 2029 & US $\$ 26,24$ & US $\$ 314,85$ & $12 \%$ & $\mathrm{R} \$ 4,80$ & $1.511,26$ & $3.022,52$ \\
\hline 2030 & US \$29,39 & US \$ 352,63 & $12 \%$ & $\mathrm{R} \$ 4,80$ & $1.692,61$ & $3.385,22$ \\
\hline & & & & Acumulado & $\mathrm{R} \$ 11.327,07$ & $\mathrm{R} \$ 22.654,14$ \\
\hline
\end{tabular}

Tabela 3

\begin{tabular}{|c|c|c|c|c|c|c|}
\hline \multicolumn{7}{|c|}{ US\$ 9,5 Trilhão } \\
\hline Ano & Monthly Yield & Annual Yield & CAGR & Dólar & $5 \%$ & $10 \%$ \\
\hline 2020 & US $\$ 15,50$ & US \$ 185,96 & $12 \%$ & $\mathrm{R} \$ 5,20$ & 967,02 & $1.934,03$ \\
\hline 2021 & US $\$ 17,36$ & US \$ 208,28 & $12 \%$ & $\mathrm{R} \$ 5,00$ & $1.041,40$ & $2.082,81$ \\
\hline 2022 & US $\$ 19,44$ & US \$233,27 & $12 \%$ & $\mathrm{R} \$ 4,80$ & $1.119,72$ & $2.239,43$ \\
\hline 2023 & US $\$ 21,77$ & US \$ 261,27 & $12 \%$ & $\mathrm{R} \$ 4,80$ & $1.254,08$ & $2.508,16$ \\
\hline 2024 & US $\$ 24,38$ & US \$292,62 & $12 \%$ & $\mathrm{R} \$ 4,80$ & $1.404,57$ & $2.809,14$ \\
\hline 2025 & US $\$ 27,31$ & US \$ 327,73 & $12 \%$ & $\mathrm{R} \$ 4,80$ & $1.573,12$ & $3.146,24$ \\
\hline 2026 & US $\$ 30,59$ & US $\$ 367,06$ & $12 \%$ & $\mathrm{R} \$ 4,80$ & $1.761,90$ & $3.523,79$ \\
\hline 2027 & US $\$ 34,26$ & US $\$ 411,11$ & $12 \%$ & $\mathrm{R} \$ 4,80$ & $1.973,32$ & $3.946,65$ \\
\hline 2028 & US $\$ 38,37$ & US $\$ 460,44$ & $12 \%$ & $\mathrm{R} \$ 4,80$ & $2.210,12$ & $4.420,24$ \\
\hline 2029 & US \$ 42,97 & US \$ 515,69 & $12 \%$ & $\mathrm{R} \$ 4,80$ & $2.475,34$ & $4.950,67$ \\
\hline 2030 & US $\$ 48,13$ & US \$ 577,58 & $12 \%$ & $\mathrm{R} \$ 4,80$ & $2.772,38$ & $5.544,75$ \\
\hline & & & & Acumulado & $\mathrm{R} \$ 18.552,96$ & $\mathrm{R} \$ \mathbf{3 7 . 1 0 5 , 9 2}$ \\
\hline
\end{tabular}

Tabela 4

\begin{tabular}{|c|c|c|c|c|c|c|}
\hline \multicolumn{7}{|c|}{ US\$ 15,4 Trilhão } \\
\hline Ano & Monthly Yield & Annual Yield & CAGR & Dólar & $5 \%$ & $10 \%$ \\
\hline 2020 & US $\$ 25,12$ & US $\$ 301,46$ & $12 \%$ & $\mathrm{R} \$ 5,20$ & $1.567,59$ & $3.135,17$ \\
\hline 2021 & US $\$ 28,14$ & US $\$ 337,63$ & $12 \%$ & $\mathrm{R} \$ 5,00$ & $1.688,17$ & $3.376,34$ \\
\hline 2022 & US $\$ 31,51$ & US $\$ 378,15$ & $12 \%$ & $R \$ 4,80$ & $1.815,12$ & $3.630,24$ \\
\hline 2023 & US \$35,29 & US \$ 423,53 & $12 \%$ & $\mathrm{R} \$ 4,80$ & $2.032,93$ & $4.065,87$ \\
\hline 2024 & US \$39,53 & US \$ 474,35 & $12 \%$ & $\mathrm{R} \$ 4,80$ & $2.276,89$ & $4.553,77$ \\
\hline 2025 & US $\$ 44,27$ & US $\$ 531,27$ & $12 \%$ & $\mathrm{R} \$ 4,80$ & $2.550,11$ & $5.100,22$ \\
\hline 2026 & US $\$ 49,59$ & US \$ 595,03 & $12 \%$ & $\mathrm{R} \$ 4,80$ & $2.856,12$ & $5.712,25$ \\
\hline 2027 & US \$55,54 & US \$ 666,43 & $12 \%$ & $\mathrm{R} \$ 4,80$ & $3.198,86$ & $6.397,72$ \\
\hline 2028 & US $\$ 62,20$ & US \$ 746,40 & $12 \%$ & $\mathrm{R} \$ 4,80$ & $3.582,72$ & $7.165,45$ \\
\hline 2029 & US $\$ 69,66$ & US $\$ 835,97$ & $12 \%$ & $\mathrm{R} \$ 4,80$ & $4.012,65$ & $8.025,30$ \\
\hline 2030 & US $\$ 78,02$ & US $\$ 936,28$ & $12 \%$ & $\mathrm{R} \$ 4,80$ & $4.494,17$ & $8.988,33$ \\
\hline & & & & Acumulado & $\mathrm{R} \$ 30.075,33$ & $\mathrm{R} \$ \mathbf{6 0 . 1 5 0 , 6 5}$ \\
\hline
\end{tabular}

\section{CONCLUSÕES}

Perante o exposto conclui-se que os dados digitais devem ser tratados como commodities, uma vez que fazem parte de mercados globais trilionários e permitem constante inovação por diversas companhias através da análise de informações. Dessa forma, os usuários podem reivindicar uma remuneração por tornarem possível os procedimentos com o constante fluxo de informações e traços comportamentais.

A grande quantidade de fluxo de dados, com volume, velocidade e variedade contribui para geração de valor em diversos setores com a aplicação de análises. As empresas mais valiosas dos Estados Unidos são grandes dependentes da coleta de informações para desenvolvimentos próprios.

O Facebook auferiu quase a integralidade de seu faturamento através da publicidade direcionada possibilitada com a classificação de perfis de usuários em grupos para facilitar o acesso à anunciantes. A 
Amazon se tornou a companhia aberta mais valiosa dos Estados Unidos com auxílio direto de técnicas de inteligência artificial para entender seus consumidores e gerar recomendações. Mas a transformação de dados em dinheiro não se resume aos titãs de tecnologia, e alcança setores como de energia, agricultura e até moda.

Não apenas as grandes companhias criam valor com a coleta e análise de dados dos usuários como também há um bilionário mercado secundário de venda de dados e informações que abrange desde farmacêuticas à hotelaria, gerando receita nas duas pontas, para corretoras que vendem os dados e as companhias que compram para aprimorar seus produtos e serviços.

Com o evento das leis de proteção de dados, os usuários podem alterar a balança da relação com as empresas e exigirem compensações pelas atividades invasivas das companhias. Os usuários agora possuem o direito de total transparência com seus dados e o direito de restringir o acesso de empresas a eles.

A proteção legislativa também cria a oportunidade de que os usuários não mais apenas cedam os dados de maneira gratuita e sem compensação. Grupos como o Data Dividend Project da Califórnia, estão prontos para negociarem um pagamento adequado para a coleta de dados dos usuários americanos. Esta iniciativa abre um precedente para que brasileiros, com LGPD, também reivindiquem pagamento.

Estudos apontam que a ampliação de análise de dados com técnicas de inteligência artificial pode gerar mais de 5 trilhões de dólares por ano globalmente, e até 15 trilhões de dólares se aplicarem técnicas de análise de dados mais abrangentes. Com a visualização de tanto valor possibilitado pelo fluxo de dados digitais, os usuários possuem argumentos sólidos para receberem sua parte por se portarem como combustível para essa economia 4.0.

No cenário brasileiro os dividendos anuais podem não ser tão empolgantes, mas utilizando juros compostos em longos períodos o acúmulo de capital pode valer a pena, uma vez que advém de atividades simples e rotineiras como um simples uso cotidiano de redes sociais. No cenário base visualiza-se dividendos médios de cerca de US\$128 ao ano para o acúmulo de quase R\$7 mil em 10 anos. Em um cenário mais amplo os dividendos anuais chegam em média a 1132 dólares, com um possível acúmulo de mais de $\mathrm{R} \$ 60$ mil em 10 anos.

Ressalta-se por fim, que se trata de uma decisão voluntária dos usuários a venda de direitos sobre seus dados digitais. As legislações de proteção de dados são criadas primeiramente em um cenário que visa privacidade, mas os utilizadores poderiam materialmente conceber o valor de seus dados através de um pagamento e se tornarem partes mais envolvidas com o processo como um todo.

\section{REFERÊNCIAS}

ACXIOM CORP. 10-K Annual Report. San Francisco: ACXIOM CORP, 2013.

ALPHABET. 2019 Annual Report. Mountain View, 2019,

AUXIER, B.; RAINIE, L.; ANDERSON, M.; PERRIN, A.; KUMAR, M.; TURNER, E.. Americans and privacy: Concerned, confused and feeling lack of control over their personal information. Pew Research Center: Internet, Science \& Tech, 2019.

BRASIL. Lei n. 13.709, de 14 de ago. de 2018. Lei Geral de Proteção de Dados Pessoais (LGPD). Brasília: DOU, 2018.

CALIFORNIA. Califórnia Consumer Privacy Act (CCPA) Sacramento, 2020. 
CALICCHIO, N.; DIAS, Y.; LOMBARDI, J.; MANSUR, M.; FLEURY, M.; CARNEIRO, A.; BERBEL, J.; BARBOSA, G.; COUTINHO, A.; DARE, C.; CRADDOCK, C.; SERTORIO, C.; BOARETTO, F.; CARVALHO, F.; BROIDE, J.; GALACHE, J.; ORLEANS, A.; REZENDE, D.; VASCONCELLOS, J.; BARRA, H.; SILVA, R. B.; LIMA, S.; BERTASOLI, V.. Brazil Digital Report. McKinsey \& Company, 2019.

CHUI, M.; MANYIKA, J.; MIREMADI, M.; HENKE, N.; CHUNG, R.; NEL, P.; MALHOTRA, S.. Notes from the Al frontier: Insights from hundreds of use cases. McKinsey Global Institute, 2018.

FTC. FTC to Study Data Broker Industry's Collection and Use of Consumer Data. Washington: FTC, 2012.

HILBERT, M; LÓPEZ, P.. The world's technological capacity to store, communicate, and compute information. Science, v.332, n.6025, p.60-65, 2011.

KIM, G; TRIMI, S; CHUNG, J.. Big-data applications in the government sector. Communications of the ACM, v.57, n.3, p.78-85, 2014.
LANIER, J.; WEYL, E. G.. A blueprint for a better digital society. Harvard Business Review, 2018.

MARR, B.. Big data in practice: how 45 successful companies used big data analytics to deliver extraordinary results. John Wiley \& Sons, 2016.

MICROSOFT. 2019 Annual Report. Redmond: Microsoft, 2019.

PEREZ, M. V.. Apple Heart Study. Stanford, 2019.

RIEKE, A.; YU, H.; ROBINSON, D.; HOBOKEN, J. V.. Data brokers in an open society. Open Society Foundations, 2016.

SHEFRIN, H.; STEPHENS-DAVIDOWITZ, S.; WAGNER, D.. Behavioral Economics in the Age of Big Data. In: ROBERT, B.. Menschel economics symposium. New York: Council on Foreign Relations, 2018.

A CBPC - Companhia Brasileira de Produção Científica (CNPJ: 11.221.422/0001-03) detém os direitos materiais desta publicação. Os direitos referem-se à publicação do trabalho em qualquer parte do mundo, incluindo os direitos às renovações, expansões e disseminações da contribuição, bem como outros direitos subsidiários. Todos os trabalhos publicados eletronicamente poderão posteriormente ser publicados em coletâneas impressas sob coordenação da Sustenere Publishing, da Companhia Brasileira de Produção Científica e seus parceiros autorizados. Os (as) autores (as) preservam os direitos autorais, mas não têm permissão para a publicação da contribuição em outro meio, impresso ou digital, em português ou em tradução. 